\title{
Development of NOx Emission and Electrochemical Detection in Atmosphere
}

\author{
Yu Du ${ }^{1}$, Xixiang Sun 1,* and Qin Wei ${ }^{2}$ \\ 1 School of Management, Wuhan University of Technology, Wuhan 430070, China; duyuwhlg@163.com, \\ xixiang_sun@126.com \\ 2 School of Chemistry and Chemical Engineering, University of Jinan, Jinan 250022, China; \\ sdjndxwq@163.com \\ * Correspondence: xixiang_sun@126.com
}

\begin{abstract}
Reactive NOx is one of the major air pollutants, which also plays a key role as greenhouse gas. Many research efforts have been devoted to not only detection of NOx in air but also abatement of NOx emission. The aim of this mini review is to provide a panoramic snapshot of the electrochemical analysis methods for the emission and detection of NOx in atmosphere, with special emphasis on NOx sensor. The electrochemical detecting mechanism and materials for fabricating electrochemical gas sensors are discussed and the prospects and challenges in this area are also evaluated. This work will serve as a useful source to inform the interested audience of the latest developments and applications in the field of NOx emission and electrochemical detection.
\end{abstract}

Keywords: $\mathrm{NO}_{2}$; $\mathrm{NO}$; gas sensor; nitrogen oxide emission; semiconductor; carbon; electrochemical

\section{Introduction}

As we all know, environmentally hazardous gases can be classified into oxidizing gases (such as $\mathrm{CO}_{2}$ and $\mathrm{Cl}_{2}$ ) and reducing gases (such as $\mathrm{H}_{2} \mathrm{~S}, \mathrm{CO}$, and $\mathrm{C}_{2} \mathrm{H}_{5} \mathrm{OH}$ )[1]. Among these gases, nitrogen oxide (NOx), which is a mixture of nitric oxide $(\mathrm{NO})$ and nitrogen dioxide $\left(\mathrm{NO}_{2}\right)$, is well known to be one of the major air pollutants containing oxidizing gas $\left(\mathrm{NO}_{2}\right)$ and reducing gas (NO)[2-4]. NOx plays a key role not only in air pollution but also as greenhouse gas, because its multiple effects can sometimes lead to various harmful reactions, such as acidification, haze, summer photochemical smog and the increase of tropospheric ozone level[5-7]. Furthermore, high concentration of NOx in air can cause headaches, various diseases, respiratory distress, and lung tissue damage [8-10]. $53 \mathrm{ppb}$ of NOx concentration in air is highly acute demanded by public the air security applications[2]. So, finding out the emission source of NOx and developing sensitive gas sensors for detecting NOx in the environment are important and critical to human health and ecological balance[11]. However, NOx cannot be avoided to generate in nature, due to it can be produced from the reaction of $\mathrm{N}_{2}$ and $\mathrm{O}_{2}$ during high-temperature combustion processes in everywhere, for example, car engines, power plants, industrial processes and even a thunderstorm[12]. So, many research efforts have been devoted to not only detection of NOx in air but also abatement of NOx emission.

Recently, several reviews focused on the development of NOx researches in environmental science. For example, in the aspect of NOx emission, Wilfried and Zbigniew reviewed the role of Ngases $\left(\mathrm{N}_{2} \mathrm{O}, \mathrm{NOx}, \mathrm{NH}_{3}\right)$ in cost-effective strategies to reduce greenhouse gas emissions and air pollution in Europe[5]. They concluded that cost efficient abatement of greenhouse gases needed to include mitigation of nitrous oxide emissions[5]. In the aspect of NOx detection, scientists synthesized various functional materials to fabricate kinds of sensor for sensitively detecting NOx via different techniques[13]. Although NOx is important for both health care and ecological protection, there is no reports to review the development of NOx emission and detection in recent years. 
In this paper, we review 81 reports in recent five years from three aspects: source and approach of NOx emission, mechanism of NOx detection and arrays for NOx detection. Our investigation and conclusion can be essential information both for policy purposes and scientific researches.

\section{Source and approach of NOx emission}

As we all know, $\mathrm{NOx}$ can be generated from the reaction of $\mathrm{N}_{2}$ and $\mathrm{O}_{2}$ during high-temperature combustion processes. So, the sources and approaches of NOx emission are very common in our daily lives, which can be divided to two parts: anthropogenic emission and natural generation.

\subsection{Anthropogenic emission}

With the development of modern science and industry, anthropogenic emission of NOx happens everywhere, such as fuel combustion, industrial manufacture, power plants, vehicle exhaust, aviation emission and so on. Among these sources and approaches, fossil fuel combustion is identified as one of the main contributors to the escalation of NOx emission[14]. For example, China is the largest energy consumer in the world and have contributed amount of various emission during past three decades because of its rapid industrializations and urbanizations. Although China has plenty of strict environment policy in recent years, $\mathrm{NO}_{x}$ emission still keeps an increase trend all the way[15].

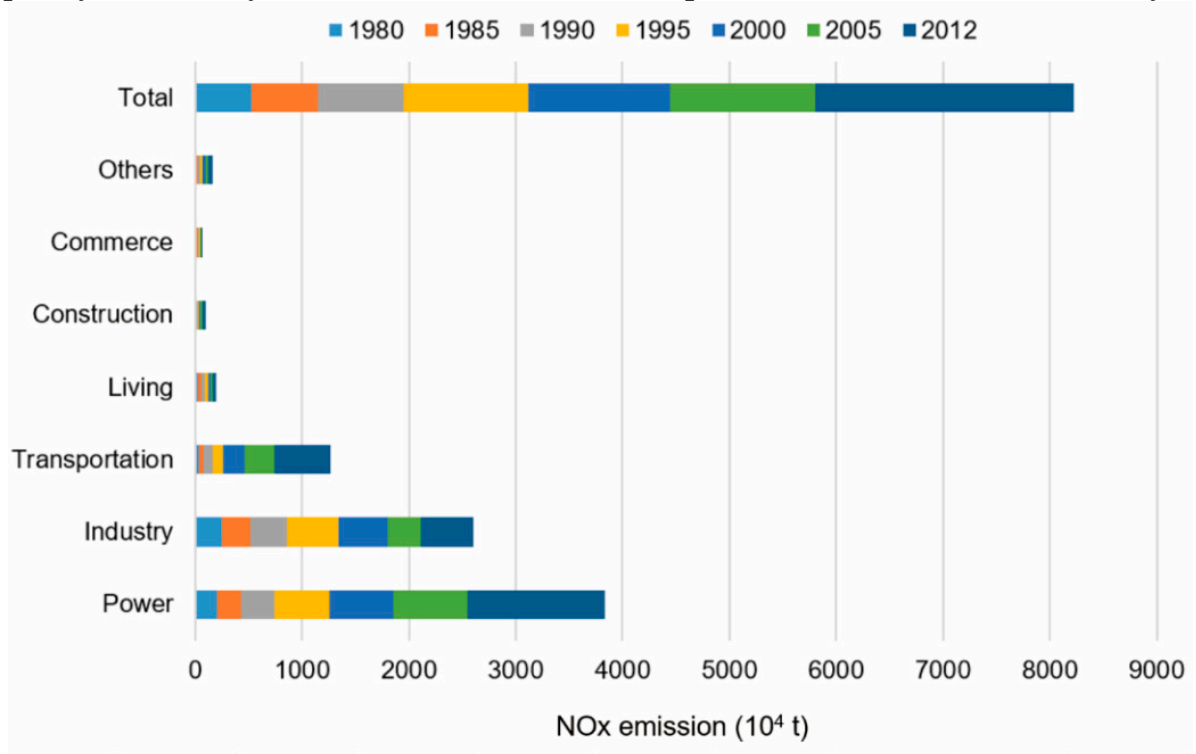

Figure 1 NOx emission of main sectors from 1980-2012 in China

Figure 1 illustrates the emissions and contributions of various sources. It can be found that the total NOx emission from various sources has increased from $446.45 \times 10^{4} \mathrm{t}$ to $2499.72 \times 10^{4} \mathrm{t}$ and increased 4.6 times from 1980 to 2012, keeping the rapid growth in recent 10 years because of energy consumption increase. Power (i.e. electricity) is the absolutely dominated contributor of NOx all the way in the past three decades, NOx emission from the electricity generating power plants has increased from $145.04 \times 10^{4} \mathrm{t}$ to $1311.6 \times 10^{4} \mathrm{t}$. Industry is the second contributor after electricity. NOx emission from industry has increased from $206.75 \times 10^{4} \mathrm{t}$ to $479.46 \times 10^{4} \mathrm{t}$ and increased about 1.31 times than that of 1980. Transportation is the fast-growing source, because NOx emission has increased from $39.44 \times 10^{4} \mathrm{t}$ to $576.31 \times 10^{4} \mathrm{t}$ and increased about 13.61 times than that 1980 . NOx emission from other sectors, including construction, residential and others, is little and takes up less than $5 \%$ of emission only.

\subsection{Natural generation}

Although anthropogenic emission is the main source and approach of NOx emission, natural generation of NOx cannot be also neglect. The production of $\mathrm{NO}_{\mathrm{x}}$ by lightning represents a large uncertainty in the global $\mathrm{NO}_{x}$ budget with estimates varying by up to two orders of magnitude, 
although the range is likely within $2-20 \mathrm{Tg}(\mathrm{N}) /$ year[16]. In addition to naturally generate from lightning during a thunderstorm, NOx can be released from biological metabolism, environmental evolution and so on[12,17]. For instance, $\mathrm{NO}$ is a ubiquitous bioactive signaling molecule. Biological $\mathrm{NO}$ is generated in the oxidation of L-arginine to L-citrulline, which is catalyzed by nitric oxide synthases. In general, this process participates in the regulation of a variety of physiological and pathological processes, such as in the control of vascular smooth muscle relaxation and vasodilation, platelet adhesion, regulation of the immune response and as a neurotransmitter in the brain[12].

\section{Electrochemical detecting mechanism}

The compounds $\mathrm{NO}$ and $\mathrm{NO}_{2}$ are radicals. Many analytical methods for detecting $\mathrm{NOx}$ are mainly based on this chemical property. Among the various techniques for NOx detection, electrochemical detection systems received extensive concerns [18-21]. Compared to alternative techniques, such as spectrophotometry[12, 22], tunable diode laser absorption spectroscopy (TDLAS)[23-25], fluorescent probe[26-29], laser diode chemiluminescence based spectroscopy methods[30], and their combined arrays[31-33], electrochemical detection systems can provide the best sensitivity and simple supporting apparatus. For example, Stranzenbach and Saruhan reported impedance-metric detection of $\mathrm{NO}$ and $\mathrm{NO}_{2}$ and yield the best results for detection of total NOx[34]. Furthermore, in these sensing approaches, electrochemical techniques are the most viable for a robust sensor, as they can provide high performance of selectivity, durability, and portability[13]. So, the electrochemical gas sensor is the most studied technique for NOx detection.

Electrochemical gas sensors, which are covered by two catalytic electrodes, consist in a ceramic ion-conducting electrolyte. In the detecting process, the general mechanism is that the response of the sensing materials is based on chemisorptions, i.e. the exchange of charge between absorbed gases and the materials surface. Therefore, the working principle of gas sensor is based on the measurement of gas adsorption and the change of conductivity caused by the surface reaction process[35]. In air, there are several different negatively charged oxygen adsorbates, such as $\mathrm{O}_{2}^{-}, \mathrm{O}^{-}$and $\mathrm{O}^{2}$, which are present in the metal oxide surface. The maximum sensor response observed in the experiments might be related with the following reactions [36]

$$
\begin{aligned}
\mathrm{O}_{2}+\mathrm{e}^{-} & \rightarrow \mathrm{O}_{2}^{-} \\
\mathrm{O}_{2}^{-}+\mathrm{e}^{-} & \rightarrow 2 \mathrm{O}^{-}
\end{aligned}
$$

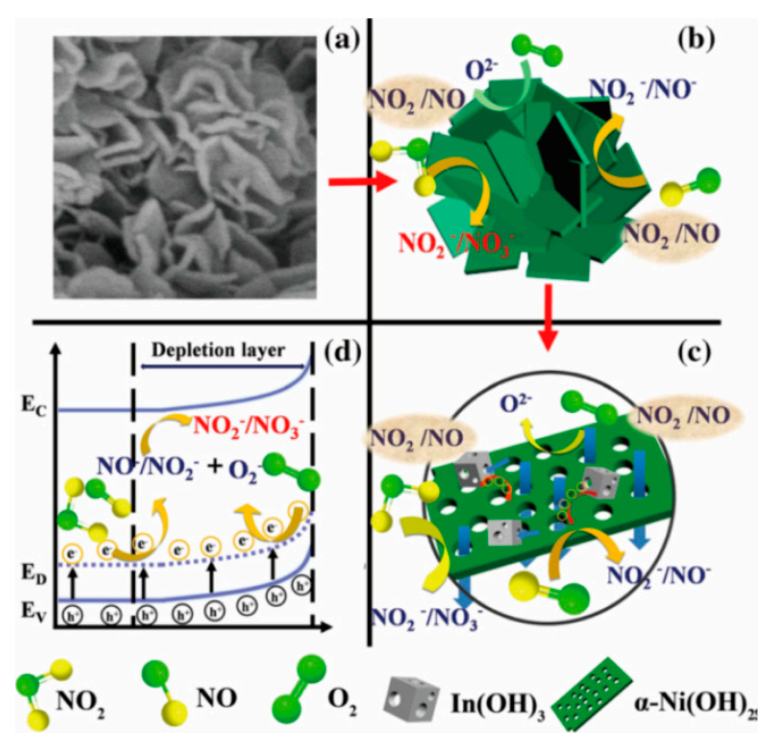

Figure 2 The gas conducting mechanism of the NOx sensor[2].

As detecting $\mathrm{NOx}$ in air, the adsorption of $\mathrm{NO}_{2}$ on the semiconductors leads to $\mathrm{NO}_{2}{ }^{-}$and the adsorption of $\mathrm{NO}$ on the semiconductors leads to NO-. Erisman and Fowler indicated that NO and $\mathrm{NO} 2$ react with the atmospheric ozone so that the quantities are transitive[37]. The process traps electrons from the conduction band or the donor level of the semiconductors, which finally leads to 
an increase of hole density. It finally results in a rapid decrease of resistances. $\mathrm{NO}_{2}$ directly adsorbs onto the semiconductors and react with $\mathrm{O}^{-}$and generate bidentate $\mathrm{NO}_{3}^{-}(\mathrm{s})$. $\mathrm{NO}$ also can adsorb onto the semiconductors and react with $\mathrm{O}^{-}$and generate $\mathrm{NO}_{2}{ }^{-}$. As discussed above, the generation of oxygen adsorbates $\left(\mathrm{O}_{2}^{-}, \mathrm{O}^{-}\right.$and $\left.\mathrm{O}^{2-}\right)$ on the semiconductors surface occurs at high temperatures, and the gas sensing response increases drastically for the metal oxide based gas sensors with particle sizes below the Debye length[38].

So, as shown in Figure 2, there are four sensing processes. First, the oxygen from the air is chemisorbed on the semiconductors surface. Second, the chemisorbed $\mathrm{O}_{2}$ can react with the electrons near the surface and transform into $\mathrm{O}_{2}{ }^{-}$at room temperature, thus decreasing the concentration of electrons near the surface and forming a depletion layer. Third, the generated oxygen adsorbent $\left(\mathrm{O}_{2}{ }^{-}\right.$ ) at the surface of semiconductors, when exposed to $\mathrm{NO}$ or $\mathrm{NO}_{2}$, the co-adsorption and mutual interaction between the gases and the adsorbed oxygen result in reduction at the surface and a decrease in the chemisorbed oxygen concentration[2]. The reactions are as follows:

$$
\begin{gathered}
\mathrm{NO}_{2}+\mathrm{e}^{-} \rightarrow \mathrm{NO}^{-} \\
\mathrm{NO}_{2}+\mathrm{e}^{-} \rightarrow \mathrm{NO}_{2}^{-} \\
\mathrm{NO}+\mathrm{O}^{-} \rightarrow \mathrm{NO}_{2}^{-} \\
\mathrm{NO}_{2}+\mathrm{O}^{-} \rightarrow \mathrm{NO}_{3}^{-}
\end{gathered}
$$

In addition to the detection of NOx in gaseous phase, the ability to detect $\mathrm{NO}$ in aqueous environments with robust and sensitive sensors would provide a means to monitor levels of dissolved NO emissions and to trace transient concentrations of NO in biomedical applications[13].

Furthermore, the interferences from other components presented in the sensing systems are not totally obviated for the systems with numerous components[39]. Do and Chen illustrated that the sensing properties of an amperometric $\mathrm{NO}$ gas sensor were significantly interfered by the presence of $\mathrm{NO}_{2}$ and $\mathrm{SO}_{2}$ in gas phase[40]. $\mathrm{Xi}$ et al. studied the effects of $\mathrm{CO}_{2}$ and $\mathrm{H}_{2} \mathrm{O}$ on the $\mathrm{NO}$ conversion performance and revealed that the presence of $\mathrm{CO}_{2}$ and $\mathrm{H}_{2} \mathrm{O}$ are beneficial to the NO reduction [41]. Moreover, the improvement by $\mathrm{H}_{2} \mathrm{O}$ was stronger than that by $\mathrm{CO}_{2}$. Friedberg and Hansen indicate that the electrochemical reduction of the nitrates when no propene is present is a surface reaction, whereas the propene enables further reduction of the bulk nitrate[42].

\section{Electrochemical detection of NOx}

Due to the harmfulness to people health and environment, it is important to develop NOx gas sensors to detect its concentrations as quickly and sensitively as possible in air. To realize this purpose, a wide variety materials with hierarchical structure provide more opportunities for exploring novel properties and superior electrochemical device performances more recently[11, 43$45]$, since this structure is often associated with a large surface area and fast gas diffusion, then leading to a better gas sensing properties in comparison with conventional nanocrystallites[2, 46-48]. At 2007, Fergus reviewed materials for high temperature electrochemical NOx gas sensor with a discussion on potentiometric sensors, impedancemetric and amperometric sensors[49]. To illustrate the methods for fabricating electrochemical NOx gas sensors more clearly, table 1 lists the recent reports on different methods of electrochemical detection of NOx.

Table 1. Different method designed for fabricating electrochemical NOx gas sensor.

\begin{tabular}{|c|c|c|c|}
\hline Methods & Target gas & Detecting temperature $/{ }^{\circ} \mathrm{C}$ & References \\
\hline Impedance spectroscopy & $\mathrm{NO}$ & $300-400$ & {$[42]$} \\
\hline Amperometric spectroscopy & $\mathrm{NO}_{2}$ & $80-160$ & {$[50]$} \\
\hline Voltammetry & $\mathrm{NO}$ & Room temperature & {$[51]$} \\
\hline Pulsed corona discharge & $\mathrm{NO}$ & Room temperature & {$[52]$} \\
\hline
\end{tabular}

In order to in-depth analysis, herein, we reviewed recent reports on electrochemical detection of NOx based on different kinds of materials used for fabricating gas sensor.

\subsection{Semiconductor oxides based gas sensor}


Semiconductor oxides are famous for their promising gas sensing properties. Tremendous efforts have been devoted to create highly responsive gas sensors based on n-type semiconductors by morphology control, doping and composites, such as $\mathrm{ZnO}, \mathrm{WO}_{3}, \mathrm{CuO}$ and $\mathrm{SnO}_{2}$ [53].

Zinc oxide $(\mathrm{ZnO})$ has already been utilized in gas sensors for detecting toxic or hazardous gases[54-57]. To enhance the sensitivity and response time of NOx sensors, $\mathrm{ZnO}$ was always combined with other materials. Recently, Zhang et al. synthesized 3D graphene aerogel-ZnO (ZnO/GAs) composites via a simple solvothermal route. In this composite, the 3D graphene not only creates a conductive matrix that provides a rapid electron channels to $\mathrm{ZnO}$ to assist in sensing process, but also acts as a confined support to prevent agglomeration and growth of the $\mathrm{ZnO}$ spheres. Additionally, 3D interconnected macroporous channels provide a large specific surface area which greatly increases the gas contact area, ensuring that the $\mathrm{NO}_{2}$ molecules easily penetrate the mesoporous. By incorporating 3D interconnected graphene with $\mathrm{ZnO}$ as conducting network, they realized rapid detection of $\mathrm{NO}_{2}$ at room temperature[53].

As another n-type oxide semiconductor, $\mathrm{WO}_{3}$ has also attracted great attention on account of its good response property to NOx gas[58-60]. To date, various $\mathrm{WO}_{3}$ nanostructures, including nanoparticles[61], nanowires[62], nanorods[63], nanosheets[64], hollow spheres[65], hierarchical spheres[66], and their hybrid compounds with other nanomaterials[60, 67, 68] have been widely investigated to accomplish high response to ppm or sub-ppm-levels of NOx. Until now, the sensitivity of the NOx sensor based on $\mathrm{WO}_{3}$ can be achieved to several tens ppb levels[45].

Although semiconducting metal oxides show good response property for NOx detection, tremendous efforts have been made to investigate the micro- or nano- composites to get higher response time and sensitivity, such as indium-doped $\mathrm{SnO}_{2}$ nanoparticle-graphene nanohybrids[69], $\mathrm{In}_{2} \mathrm{O}_{3}-\mathrm{xBaO}\left(\mathrm{x}=0.5-5\right.$ at.\%)[70], $\mathrm{SnO}_{2} / 3 \mathrm{D}$ graphene aerogel[71], ITO- $\mathrm{SnO}_{2}$ [72], Cr-doped $\mathrm{CuO}$ nanorods[73], and p-porous silicon(substrate)/ $\mathrm{p}-\mathrm{TeO}_{2}$ (nanowires)[74], etc.

\subsection{Carbon materials based gas sensor}

As we discussed above, metal oxides are well-known materials suitable for detecting a wide spectrum of gases with enough sensitivity. However, these materials are typically operated at temperatures that range between 200 and $800{ }^{\circ} \mathrm{C}$. The reason is that the mobility of oxygen vacancies becomes appreciable and the mechanism of conduction becomes mixed ionic-electronic at higher temperatures. The diffusion of oxygen vacancies is known to be a mechanism responsible for longterm drift in metal oxide gas sensors $[35,36]$. Therefore, a strategy to avoid long-term changes in their response could consist in operating the sensors at temperatures low enough so that appreciable structural variation never occurs, provided that gas reactions occur at a reasonable rate. So carbon micro- or nano- materials can be utilized to composite with other materials to realize this purpose.

Based on multiwall carbon nanotube(MWCNTs), Espinosa et al. prepared oxygenfunctionalized MWCNTs composited with three different types of metal oxides $\left(\mathrm{SnO}_{2}, \mathrm{WO}_{3}\right.$ and $\left.\mathrm{TiO}_{2}\right)$ hybrid films[75]. They discovered that the addition of a small quantity of $\mathrm{O}_{2}$-functionalized MWCNTs to metal oxides can significantly improve the detection capability of a metal oxide based sensor at low operating temperatures. They also concluded that there should be an optimum amount of carbon nanotubes to be added to each particular metal oxide in order to enhance responsiveness.

Graphene based sensors have the ability to detect even a single molecular species due to the tunable electrical conductivity caused by the chemical doping from the adsorbed molecules[76, 77]. Furthermore, due to its good electrical conductivity, it always acts as a conducting channel[69]. For example, because of the extraordinary electrical properties and ultra large specific surface area of graphene, Wang et al. fabricated more excellent gas sensing properties based on the $\operatorname{In}_{2} \mathrm{O}_{3}$-reduced graphene oxide $\left(\mathrm{In}_{2} \mathrm{O}_{3}-\mathrm{rGO}\right)$ nanocomposites. They prepared n-type $\mathrm{In}_{2} \mathrm{O}_{3}-\mathrm{rGO}$ nanocomposites via a facile hydrothermal method, which exhibited excellent selectivity, high response, and relatively short response/recovery time for the detection of $\mathrm{NO}_{2}$ at room temperature.

\subsection{Other materials based gas sensor}


$\alpha-\mathrm{Ni}(\mathrm{OH})_{2}$ that is composed of $\mathrm{NiOH}$ layers or nanosheets has a typical $\mathrm{LDH}$ structure. Generally, the layered double hydroxide-like (LDHs-like) structure has always shown a gallery pathway facilitating carrier diffusion/ transportation throughout the entire particle bulk. It is benefit for improving the sensing response time, and the charge carriers only need to diffuse a very short (subnanometer) distance before reaching the surface of the unit sheets in a LDHs-like structure. Therefore, LDHs-like structure materials might be a favorable material for gas detection. Wang et al. prepared a highly mesoporous hierarchical nanostructure $\mathrm{Ni}(\mathrm{OH})_{2}-\mathrm{In}(\mathrm{OH})_{3}$ composite assembled by nanosheets via one pot facile reflux method were reported. The gas sensor exhibited excellent sensing properties at ultralow detection limit of $9.7 \mathrm{ppb}$ for detection of NOx and the response toward 97 ppm NOx could reach to $60 \%$ and the response time was $1.2 \mathrm{~s}$.

$\mathrm{MoS}_{2}$, which is a graphene-like two-dimensional (2D) layered transition metal dichalcogenide material, has attracted enormous interest for its promising semiconducting characteristics and the advantageous band gap than graphene. Compared with graphene of zero band gap, the unique monolayer $\mathrm{MoS}_{2}$ intriguingly shows a desirable and direct band gap of $1.90 \mathrm{eV}$. The intrinsic semiconductor nature and large surface-to-volume ratio make monolayer $\mathrm{MoS}_{2}$ appropriate in chemical sensors. And recently, $\mathrm{MoS}_{2}$ films based on transistor sensors have been experimentally demonstrated to show stable sensitivity towards NO gas molecules[78, 79].

Based on the above discussion, to illustrate the other materials used to fabricate the electrochemical NOx gas sensors more clearly, table 2 show the recent reports on electrochemical detection of NOx based on other different kinds of materials used for fabricating gas sensor.

Table 2. Other different kinds of materials used for fabricating electrochemical NOx gas sensor.

\begin{tabular}{|c|c|c|c|c|}
\hline Type of materials & Representative materials & $\begin{array}{c}\text { Target } \\
\text { gas }\end{array}$ & $\begin{array}{c}\text { Limit of } \\
\text { detection } \\
\text { (LOD) }\end{array}$ & References \\
\hline $\begin{array}{c}\text { Metal organic } \\
\text { framework (MOF) }\end{array}$ & $\begin{array}{c}\mathrm{Cu}-3(\mathrm{BTC})(2) \text { (copper(II) benzene } \\
\text { 1,3,5-tricarboxylate) }\end{array}$ & $\mathrm{NO}$ & $5 \mathrm{ppb}$ & {$[80]$} \\
\hline Ionic liquid & $\begin{array}{c}\text { 1-ethyl-3-methylimidazolium } \\
\text { bis(trifluoromethylsulfonyl)imide } \\
\text { ([EMIM][N(Tf) }] \text { ) }\end{array}$ & $\mathrm{NO}_{2}$ & $0.3 \mathrm{ppb}$ & {$[50]$} \\
\hline Enzyme & $\begin{array}{c}\text { Copper nitrite reductase } \\
\text { Hemin on a ZnO-PPy } \\
\text { nanocomposite }\end{array}$ & $\mathrm{NO}_{2}$ & - & {$[18]$} \\
\hline Metalloporphyrins & \multicolumn{2}{|c|}{$0.8 \mu \mathrm{m}$} & {$[81]$} \\
\hline
\end{tabular}

\section{Conclusion and challenge}

In this review, we investigated the source of NOx emission in China from 1980 to 2012, and the results indicated that NOx emission had increased 4.6 times during the past 32 years and had an apparent upward trend in recent years, because of rapid energy consumption industrial development and living improvement. Recent years have also witnessed tremendous advances towards the considerable interest to NOx detection. Of all the NOx detection research, hybrid films based on semiconductor oxides or carbon have been used as gas sensitive materials with improved sensitivity. These works indicate that the detection at ambient temperature of NOx can be highly improved with novel nanomaterial. More importantly, porous materials, especially mesoporous materials, which have been used as not only base substrate but also reactive materials, have emerged to show excellent adsorption and sensitivity towards NOx. However, although these types of devices are highly sensitive to low ppm levels, some limitations such as cross response issues to other gases and humidity levels and limited lifetimes along with the complications in the fabrication should keep on improving.

Acknowledgments: This work was supported by the Natural Science Foundation of China (No. 21375047), the National Social Science Foundation of China (No.11CJY039), Humanities and Social Science Foundation of the 
Ministry of Education (No. 13YJC790059), the Natural Science Foundation of Shandong (ZR2015DM014), and Humanities and Social Science Foundation of Shandong Provincial Department of Education (No. J12WG59).

Conflicts of Interest: The authors declare no conflict of interest.

\section{References}

1. Akamatsu, T., et al., NO and NO2 sensing properties of WO3 and Co3O4 based gas sensors. Sensors, 2013. 13(9): p. 12467-12481.

2. Wang, J.C., et al., Detection of NOx down to ppb levels at room temperature based on highly mesoporous hierarchical $\mathrm{Ni}(\mathrm{OH})(2)-\mathrm{In}(\mathrm{OH})(3)$ double hydroxide composites. Journal of Materials Science-Materials in Electronics, 2015. 26(9): p. 6612-6624.

3. Rahm, M., et al., Experimental Detection of Trinitramide, N(NO2)(3). Angewandte ChemieInternational Edition, 2011. 50(5): p. 1145-1148.

4. Sguera, C., P. Galeano, and R.E. Lillo, Functional outlier detection by a local depth with application to NO (x) levels. Stochastic Environmental Research and Risk Assessment, 2016. 30(4): p. 11151130.

5. Winiwarter, $\mathrm{W}$. and Z. Klimont, The role of $\mathrm{N}$-gases (N $2 \mathrm{O}, \mathrm{NO} x, \mathrm{NH} 3$ ) in cost-effective strategies to reduce greenhouse gas emissions and air pollution in Europe. Current Opinion in Environmental Sustainability, 2011. 3(5): p. 438-445.

6. Zheng, D., et al., An Electrochemical Microsensor for the Detection of Nitric Oxide. Analytical Letters, 2013. 46(5): p. 790-802.

7. Tsikas, D., J. Sandmann, and B. Beckmann, Analysis of NO and its metabolites by mass spectrometry. Comment on 'Detection of nitric oxide in tissue samples by ESI-MS' by Z. Shen, A. Webster, K. J. Welham, C. E. Dyer, J. Greenman and S. J. Haswell. Analyst, 2011. 136(2): p. 407-410.

8. Kim, H.S., K.U. Jang, and T.W. Kim, $N O(x)$ gas detection characteristics in FET-type multi-walled carbon nanotube-based gas sensors for various electrode spacings. Journal of the Korean Physical Society, 2016. 68(6): p. 797-802.

9. Haisch, C. and R. Niessner, Photoacoustic Analyzer for the Artifact-Free Parallel Detection of Soot and NO2 in Engine Exhaust. Analytical Chemistry, 2012. 84(17): p. 7292-7296.

10. Sano, Y., et al., Bioluminescent Assay for Nitric Oxide Utilizing the Biological Enzyme Activity of Soluble Guanylate Cyclase. Analytical Letters, 2011. 44(17): p. 2834-2840.

11. Ma, D., et al., The adsorption of $\mathrm{CO}$ and $\mathrm{NO}$ on the MoS2 monolayer doped with $\mathrm{Au}, \mathrm{Pt}, \mathrm{Pd}$, or Ni: A first-principles study. Applied Surface Science, 2016. 383: p. 98-105.

12. Marti, A., et al., Selective colorimetric $N O(g)$ detection based on the use of modified gold nanoparticles using click chemistry. Chemical Communications, 2015. 51(15): p. 3077-3079.

13. Sund, J.B., et al., Diamond for Biosensing: Electrochemical Detection of NOx Species with ThiolAmine Functionalized Diamond. Journal of the Electrochemical Society, 2015. 162(8): p. B225B229.

14. Dincer, I., Environmental impacts of energy. Energy Policy, 1999. 27(14): p. 845-854.

15. Kurokawa, J.I., et al., Adjoint inverse modeling of NO $x$ emissions over eastern China using satellite observations of NO 2 vertical column densities. Atmospheric Environment, 2009. 43(11): p. 18781887.

16. Skamarock, W.C., et al., Observational-and modeling-based budget of lightning-produced NOx in a 
continental thunderstorm. Journal of Geophysical Research Atmospheres, 2003. 108(10): p. 535548.

17. Ignarro, L.J., Nitric oxide : biology and pathobiology. 2000: Academic Press.

18. Maji, R.C., et al., Copper Complexes Relevant to the Catalytic Cycle of Copper Nitrite Reductase: Electrochemical Detection of $\mathrm{NO}(\mathrm{g})$ Evolution and Flipping of $\mathrm{NO} 2$ Binding Mode upon $\mathrm{Cu}-\mathrm{II}->\mathrm{Cu}$ I Reduction. Inorganic Chemistry, 2013. 52(19): p. 11084-11095.

19. Jakoby, B., et al., Eurosensor XXIV ConferenceEffect of nanostructured WO3 layers in the sensitivity to nitrogen oxide in YSZ-based electrochemical sensors for automotive applications. Procedia Engineering, 2010. 5: p. 164-167.

20. Valentini, F., et al., Glassy carbon electrodes modified with hemin-carbon nanomaterial films for amperometric $\mathrm{H} 2 \mathrm{O} 2$ and NO2- detection. Electrochimica Acta, 2012. 63: p. 37-46.

21. Ozdemir, S., T.B. Osburn, and J.L. Gole, Nanostructure Modified Gas Sensor Detection Matrix for NO Transient Conversion of NO to NO2. Journal of the Electrochemical Society, 2011. 158(7): p. J201-J207.

22. Liu, B., et al., Application of nanodiamonds in $\mathrm{Cu}(\mathrm{II})$-based rhodamine $\mathrm{B}$ probes for $\mathrm{NO}$ detection and cell imaging. Journal of Materials Chemistry B, 2016. 4(19): p. 3358-3364.

23. Kohring, M., et al., QCL-based TDLAS sensor for detection of NO toward emission measurements from ovarian cancer cells. Applied Physics B-Lasers and Optics, 2014. 117(1): p. 445-451.

24. Qian, Y.X. and H.J. Sun, Improved approach for ultra-sensitive detection of NO. Optics Express, 2011. 19(2): p. 739-747.

25. Zheng, H.D., et al., Scattered light modulation cancellation method for sub-ppb-level NO2 detection in a LD-excited QEPAS system. Optics Express, 2016. 24(10).

26. Kumar, N., V. Bhalla, and M. Kumar, Recent developments of fluorescent probes for the detection of gasotransmitters (NO, CO and H2S). Coordination Chemistry Reviews, 2013. 257(15-16): p. 2335-2347.

27. Juarez, L.A., et al., A new chromo-fluorogenic probe based on BODIPY for NO2 detection in air. Chemical Communications, 2015. 51(9): p. 1725-1727.

28. Juarez, L.A., et al., A Boron Dipyrromethene (BODIPY)-Based Cu-II-Bipyridine Complex for Highly Selective NO Detection. Chemistry-a European Journal, 2015. 21(44): p. 15486-15490.

29. Chen, J.B., et al., Boron-chelating fluorescent probe (BOPB) in the red region combined with CE-LIF for the detection of NO in mice liver. Electrophoresis, 2016. 37(4): p. 609-615.

30. Wang, S., et al., Satellite detection and model verification of NOx emissions from power plants in Northern China. Environmental Research Letters, 2010. 5(4): p. 44007-44013(7).

31. Mosley, J., T. Cline, and J.C. Hansen, Laser-induced fluorescence detection of NO2. Abstracts of Papers of the American Chemical Society, 2012. 243.

32. Yehya, F. and A.K. Chaudhary, Study of damping, saturation and surface losses on low level detection of NO2 using time resolved pulsed photo acoustic technique. Optics Communications, 2014. 312: p. 16-22.

33. Chao, X., J.B. Jeffries, and R.K. Hanson, Wavelength-modulation-spectroscopy for real-time, in situ NO detection in combustion gases with a 5.2 mu m quantum-cascade laser. Applied Physics BLasers and Optics, 2012. 106(4): p. 987-997.

34. Stranzenbach, M. and B. Saruhan, Equivalent circuit analysis on NOx impedance-metric gas sensors. Sensors and Actuators B: Chemical, 2009. 137(1): p. 154-163. 
35. Sharma, A., M. Tomar, and V. Gupta, Room temperature trace level detection of NO2 gas using SnO2 modified carbon nanotubes based sensor. Journal of Materials Chemistry, 2012. 22(44): p. 23608-23616.

36. Rajesh, N., et al., Investigation of CdO nanostructures synthesized by microwave assisted irradiation technique for NO2 gas detection. Journal of Alloys and Compounds, 2014. 607: p. 54-60.

37. Erisman, J.W. and D. Fowler, Oxidized and Reduced Nitrogen in the Atmosphere. 2004: Environmental and Ecological Chemistry.

38. Yang, Y., et al., A novel gas sensor based on porous alpha-Ni(OH)(2) ultrathin nanosheet/reduced graphene oxide composites for room temperature detection of NOx. New Journal of Chemistry, 2016. 40(5): p. 4678-4686.

39. Do, J.S. and P.J. Chen, Amperometric sensor array for NO x, CO, O 2 and SO 2 detection. Sensors \& Actuators B Chemical, 2007. 122(1): p. 165-173.

40. Do, J.S., K.J. Wu, and M.L. Tsai, Amperometric NO gas sensor in the presence of diffusion barrier: selectivity, mass transfer of NO and effect of temperature. Sensors \& Actuators B Chemical, 2002. 86(1): p. 98-105.

41. Wang, X., et al., Mechanistic modeling of NO electrochemical reduction in a micro-tubular cell: Effects of $\mathrm{CO} 2 / \mathrm{H} 2 \mathrm{O}$ components and electrochemical promotion. Chemical Engineering Journal, 2015. 280: p. 1-8.

42. Friedberg, A.Z. and K.K. Hansen, Electrochemical reduction of NO with propene in the presence of oxygen on LSCoM/CGO porous cell stacks impregnated with BaO. Journal of Solid State Electrochemistry, 2015. 19(6): p. 1611-1620.

43. Ionescu, R., et al., Novel hybrid materials for gas sensing applications made of metal-decorated MWCNTs dispersed on nano-particle metal oxides. Sensors and Actuators B: Chemical, 2008. 131(1): p. 174-182.

44. Wang, Z.Y., et al., Preparation of Ag nanoparticles-SnO2 nanoparticles-reduced graphene oxide hybrids and their application for detection of NO2 at room temperature. Sensors and Actuators BChemical, 2016. 222: p. 893-903.

45. Kim, J.S., et al., Highly sensitive and selective detection of ppb-level NO2 using multi-shelled WO3 yolk-shell spheres. Sensors and Actuators B-Chemical, 2016. 229: p. 561-569.

46. Yong, Y.L., et al., W@Si-12 cluster as a potential sensor for CO and NO detection. Epl, 2015. 111(1).

47. Wang, L.L., et al., Concave Cu2O octahedral nanoparticles as an advanced sensing material for benzene (C6H6) and nitrogen dioxide (NO2) detection. Sensors and Actuators B-Chemical, 2016. 223: p. 311-317.

48. Bishop, C., et al., Highly sensitive detection of NO2 gas using BGaN/GaN superlattice-based double Schottky junction sensors. Applied Physics Letters, 2015. 106(24).

49. Fergus, J.W., Materials for high temperature electrochemical NOx gas sensors. Sensors and Actuators B: Chemical, 2007. 121(2): p. 652-663.

50. Kubersky, P., et al., An Electrochemical NO2 Sensor Based on Ionic Liquid: Influence of the Morphology of the Polymer Electrolyte on Sensor Sensitivity. Sensors, 2015. 15(11): p. 28421-28434.

51. Wang, L., et al., Fabrication of electrochemical NO sensor based on nanostructured film and its application in drug screening. Biosensors \& Bioelectronics, 2013. 50: p. 57-61.

52. Zhao, L., et al., Energy Consumption Analysis and OH Radical Detection of NO Conversion Process from Flue Gas Using Pulsed Corona Discharge. Ieee Transactions on Plasma Science, 2014. 42(1): 
p. 105-113.

53. Liu, X., J.B. Sun, and X.T. Zhang, Novel 3D graphene aerogel-ZnO composites as efficient detection for NO2 at room temperature. Sensors and Actuators B-Chemical, 2015. 211: p. 220-226.

54. Chougule, M.A., et al., Development of nanostructured $\mathrm{ZnO}$ thin film sensor for NO2 detection. Journal of Experimental Nanoscience, 2014. 9(5): p. 482-490.

55. Li, J., W.G. Zhang, and J.B. Sun, Enhanced NO2 detection using hierarchical porous ZnO nanoflowers modified with graphene. Ceramics International, 2016. 42(8): p. 9851-9857.

56. Andringa, A.M., et al., Gate-Bias Controlled Charge Trapping as a Mechanism for NO2 Detection with Field-Effect Transistors. Advanced Functional Materials, 2011. 21(1): p. 100-107.

57. Orabona, E., et al., On mechanism of NO2 detection by $\mathrm{ZnO}$ excitonic luminescence. Sensors and Actuators B-Chemical, 2015. 210: p. 706-711.

58. Hu, M., et al., Porous WO3 from anodized sputtered tungsten thin films for NO2 detection. Applied Surface Science, 2011. 258(3): p. 1062-1068.

59. Lopez-Gandara, C., et al., Role of nanostructured WO3 in ion-conducting sensors for the detection of NOx in exhaust gases from lean combustion engines. Solid State Ionics, 2011. 184(1): p. 83-87.

60. Varsani, P., et al., Zeolite-modified WO3 gas sensors - Enhanced detection of NO2. Sensors and Actuators B-Chemical, 2011. 160(1): p. 475-482.

61. Meng, Z., et al., Morphological and crystal structural control of tungsten trioxide for highly sensitive NO2 gas sensors. Journal of Materials Chemistry C, 2015. 3(5): p. 1134-1141.

62. Ponzoni, A., et al., Ultrasensitive and highly selective gas sensors using three-dimensional tungsten oxide nanowire networks. Applied Physics Letters, 2006. 88(20): p. 203101.

63. Bai, S., et al., Low-temperature hydrothermal synthesis of WO3 nanorods and their sensing properties for NO2. Journal of Materials Chemistry, 2012. 22(25): p. 12643-12650.

64. Kida, T., et al., WO3 Nanolamella Gas Sensor: Porosity Control Using SnO2 Nanoparticles for Enhanced NO2 Sensing. Langmuir, 2014. 30(9): p. 2571-2579.

65. Wang, C., et al., One-pot synthesis of hierarchical WO3 hollow nanospheres and their gas sensing properties. RSC Advances, 2015. 5(38): p. 29698-29703.

66. Li, J., et al., Hydrothermal synthesis of self-assembled hierarchical tungsten oxides hollow spheres and their gas sensing properties. Acs Applied Materials \& Interfaces, 2015. 7(19).

67. Huang, J., et al., Preparation of polythiophene/WO3 organic-inorganic hybrids and their gas sensing properties for NO2 detection at low temperature. Journal of Natural Gas Chemistry, 2011. 20(4): p. 403-407.

68. Su, P.-G. and T.-T. Pan, Fabrication of a room-temperature NO2 gas sensor based on WO3 films and WO3/MWCNT nanocomposite films by combining polyol process with metal organic decomposition method. Materials Chemistry and Physics, 2011. 125(3): p. 351-357.

69. Cui, S.M., et al., Indium-doped SnO2 nanoparticle-graphene nanohybrids: simple one-pot synthesis and their selective detection of NO2. Journal of Materials Chemistry A, 2013. 1(14): p. 4462-4467.

70. Shekhar, C., et al., In2O3+xBaO ( $x=0.5-5$ at. \%) - A novel material for trace level detection of NOx in the ambient. Sensors and Actuators B-Chemical, 2011. 155(1): p. 19-27.

71. Liu, X., et al., 3D graphene aerogel-supported SnO2 nanoparticles for efficient detection of NO2. Rsc Advances, 2014. 4(43): p. 22601-22605.

72. Madhi, I., M. Saadoun, and B. Bessais, Screen Printed ITO-SnO2 Nanocomposite Films for NO2 Detection. Sensor Letters, 2011. 9(5): p. 1726-1730. 
73. Kim, K.M., et al., Selective Detection of NO2 Using Cr-Doped CuO Nanorods. Sensors, 2012. 12(6): p. 8013-8025.

74. Wu, Y.Q., et al., Enhanced response characteristics of p-porous silicon (substrate)/p-TeO2 (nanowires) sensor for NO2 detection. Sensors and Actuators B-Chemical, 2014. 195: p. 181-188.

75. Espinosa, E.H., et al., Hybrid metal oxide and multiwall carbon nanotube films for low temperature gas sensing. Sensors and Actuators B: Chemical, 2007. 127(1): p. 137-142.

76. Pearce, R., et al., Epitaxially grown graphene based gas sensors for ultra sensitive NO2 detection. Sensors and Actuators B-Chemical, 2011. 155(2): p. 451-455.

77. Sridevi, S., et al., Ultra sensitive NO2 gas detection using the reduced graphene oxide coated etched fiber Bragg gratings. Sensors and Actuators B-Chemical, 2016. 223: p. 481-486.

78. Ding, K.N., Y.H. Lin, and M.Y. Huang, The enhancement of NO detection by doping strategies on monolayer MoS2. Vacuum, 2016. 130: p. 146-153.

79. Li, H., et al., Fabrication of Single- and Multilayer MoS2 Film-Based Field-Effect Transistors for Sensing NO at Room Temperature. Small, 2012. 8(1): p. 63-67.

80. Liu, Z.-Z., et al., Electrochemical Synthesis of Cu-3(BTC)(2)-MOF for Selective Catalytic Reduction of NO with NH3. Acta Physico-Chimica Sinica, 2015. 31(12): p. 2366-2374.

81. Prakash, S., et al., Electrochemical incorporation of hemin in a ZnO-PPy nanocomposite on a Pt electrode as NOx sensor. Analyst, 2012. 137(24): p. 5874-5880.

(C) 2016 by the authors; licensee Preprints, Basel, Switzerland. This article is an open access article distributed under the terms and conditions of the Creative Commons by Attribution (CC-BY) license (http://creativecommons.org/licenses/by/4.0/). 